\title{
Training and transfer effects in task switching
}

\author{
Meredith Minear \\ Washington University, St. Louis, Missouri \\ AND \\ PRITI SHAH \\ University of Michigan, Ann Arbor, Michigan
}

\begin{abstract}
Performance on task switching, a paradigm commonly used to measure executive function, has been shown to improve with practice. However, no study has tested whether these benefits are specific to the tasks learned or are transferable to new situations. We report evidence of transferable improvement in a cued, randomly switching paradigm as measured by mixing cost, but we report no consistent improvement for switch cost. Improvement in mixing costs arises from a relative reduction in time to perform both switch and nonswitch trials that immediately follow switch trials, implicating the ability to recover from unexpected switches as the source of improvement. These results add to a growing number of studies demonstrating generalizable improvement with training on executive processing.
\end{abstract}

Task switching is an increasingly popular method used in studies of cognitive control. In the typical taskswitching paradigm, a participant must switch between two simple tasks, such as adding 3 to a number on one trial and then subtracting 3 on the next. When participants alternate between two tasks, their reaction times (RTs) are slower than when repeating a single task.

Although the task-switching paradigm was originally developed by Jersild (1927), its use has only recently become widespread, due to a growing interest in executive function. Executive functions are supervisory processes that allow for top-down control of action and are essential for goal-directed behavior. Task switching has been proposed as a candidate executive function along with inhibition, the maintenance and updating of information in working memory, and the ability to perform two tasks at the same time (Miyake et al., 2000). Moreover, task switching has been used to study executive processing across psychology and related fields, including cognitive development (Cepeda, Kramer, \& Gonzalez de Sather, 2001), cognitive aging (Kramer, Hahn, \& Gopher, 1999; Kray \& Lindenberger, 2000, Mayr, 2001), and brain imaging (Braver, Reynolds, \& Donaldson, 2003; Sohn, Ursu, Anderson, Stenger, \& Carter, 2000), and in studies of a wide array of clinical disorders, including attention deficit hyperactivity disorder (Cepeda, Cepeda, \& Kramer, 2000), Parkinson's disease (Meiran, Friedman, \& Yehene, 2004), and frontal lobe injury (Keele \& Rafal, 2000).

Given the importance of executive functions and the effects that impairment of these functions have on numerous populations, there is growing interest in determining whether performance on executive control can be improved with practice (Verhaeghen, Cerella, \& Basak, 2004) and whether it can show transfer to unpracticed situations. There is some evidence not only that the efficiency of executive functions, such as inhibition (Dowsett \& Livesey, 2000), working memory (Klingberg, Forssberg, \& Westerberg, 2002), and dual-task performance (Bherer et al., 2005; Kramer, Larish, \& Strayer, 1995), improves with practice, but also that this improvement can transfer to novel contexts. There are demonstrable practice-related improvements in switching performance (Jersild, 1927; Kramer et al., 1999; Kray \& Eppinger, 2006; Kray \& Lindenberger, 2000; Mayr \& Kliegl, 2003; Meiran, 1996). However, there has been no direct test of whether the observed performance improvements constitute a transferable improvement in the ability to switch tasks more efficiently or are simply an improvement in the practiced task. In the present study, we investigated the extent to which improved task-switching performance with practice can transfer to a new task-switching situation. We employed a pretest-posttest design in which participants were measured on their ability to switch between two tasks, both before and after practice on other switching tasks.

\section{TASK SWITCHING AND IMPROVEMENTS WITH PRACTICE}

Cognitive control has been proposed as being necessary to task switching on a variety of levels. Participants must select and maintain the currently relevant goal, inhibit currently irrelevant aspects of the stimulus, and suppress stimulus-response mappings belonging to the competing task. Rogers and Monsell (1995) introduced

M. Minear, mereditheminear@gmail.com 
the term task-set reconfiguration to describe the proposed set of control processes necessary when switching tasks. Task-set reconfiguration is measured in terms of its switch cost, which is determined by comparing the average RT on the switch trials with the average on the nonswitch trials within a switch block. However, other researchers view the difference between switch and nonswitch trials as arising less from the cost of a switch and more from a repetition benefit for nonswitch trials due to various forms of priming (Dreisbach, Haider, \& Kluwe, 2002; Sohn \& Carlson, 2000; Wylie \& Allport, 2000) or to cue encoding and retrieval benefits (Mayr \& Kliegl, 2003; D. W. Schneider \& Logan, 2005). Of these two interpretations, only task-set reconfiguration allows for the possibility of transferable improvement in task switching as measured by the switch cost, whereas priming effects and cue-based retrieval processes would seem unlikely to generalize across one set of tasks to another.

A different perspective suggests that cognitive control is necessary on both the switch and the nonswitch trials within a switching block. Although no explicit task-set reconfiguration is needed on nonswitch trials, the stimulus may still evoke the currently irrelevant task set, which must be inhibited momentarily, but not abandoned completely, because it will be needed on future trials. Therefore, some task-switching research also uses mixing cost as a measure of cognitive control. Mixing cost is the comparison of the average RT of trials from single-task blocks with the average RT of nonswitch trials within a switching block. Proposed sources of mixing cost include the control processes necessary for resolving stimulus ambiguity (Rubin \& Meiran, 2005) and for maintaining multiple task sets and selecting from them (Mayr, 2003). Such processes may include the ability to focus attention on relevant aspects and to inhibit irrelevant aspects of the stimulus and the response sets. However, other researchers view mixing cost as simply reflecting differences in arousal and working memory load between single-task and switching blocks (Rogers \& Monsell, 1995).

Both mixing and switch costs show substantial reduction with practice (Cepeda et al., 2001; Kray \& Lindenberger, 2000; Meiran, 1996). For individual trial types, this means that nonswitch trials show greater practice-based reductions than do single-task trials and that switch trials show larger reductions than do nonswitch trials. However, whether the same pattern is present in any possible transfer remains to be determined.

\section{EXPERIMENT 1}

This experiment was designed to establish the extent to which practice-based reductions in two measures of switching cost can transfer to a new switching situation. We used a pretest-posttest design in which switching between paired transfer tasks was measured before and after participants either received training in switching with three pairs of tasks that were different from the pretest-posttest tasks or engaged in single-task practice with the same six training tasks. In addition, we used two variants of the task-switching paradigm, predictable switching and random switching.
In predictable switching, the participant knows the taskswitching sequence (e.g., the two tasks alternate every two trials) so that it is known beforehand whether the next trial type will be switch or nonswitch. In random switching, the task sequence is unpredictable, and the appropriate task on each trial must be indicated by a cue. On any given trial, both predictable and random switching require participants to inhibit the irrelevant aspects of both the stimulus and the inappropriate response set and to perform task-set reconfiguration on switch trials. However, differences between predictable and random switches have been reported for both mixing costs (Kray, Li, \& Lindenberger, 2002) and switch costs (Milán, Sanabria, Tornay, \& González, 2005; Monsell, Sumner, \& Waters, 2003; Tornay \& Milán, 2001), leading some researchers to propose that the demand for controlled processing is greater in random switching than in predictable switching (Tornay \& Milán, 2001), whereas others have concluded the opposite (Milán et al., 2005; Monsell et al., 2003). Therefore, we included a block of predictable switching and a block of random switching at pretest and at posttest. We had three mutually exclusive groups of participants, one trained on predictable switching, one trained on random switching, and one that practiced the same tasks, but in single-task blocks that did not require switching between tasks. This allowed us to test not only whether transfer of training was possible for two types of task-switch, but also whether practice on one would transfer to the other.

\section{Method}

Participants. Ninety-three University of Michigan undergraduates participated for a $\$ 20$ payment and were randomly assigned to each group: predictable switch-training $(n=31)$, random switchtraining $(n=31)$, and control $(n=31)$.

Design. To test for transferable improvement in switching performance, we used a pretest-posttest design in which all three groups were measured initially on a block of predictable switching and on a block of random switching. The experiment was conducted across 2 days. On Day 1, pretest switching performance was measured, after which each group was given a different course of training. One group practiced predictable switching between the tasks in three different task pairs; one practiced switching between the tasks in the same pairs, but with random switches; and one practiced performing each of the six tasks in isolation. On Day 2, all three groups continued their particular course of training, followed by the posttest measurement on predictable and random switching. Transfer of training would be indicated by differential pretest-to-posttest improvement between groups.

Tasks and Stimuli. Four task pairs were used: one at pre- and posttest and three during training. All tasks required simple judgments about numbers or letters and used the same two response keys, designated the "left" and "right" keys. In predictable switching, the task switched every other trial (AABBAA ...), whereas in random switching, the two tasks were allowed to change at random, with the constraint that half of the trials were switches, so that both the predictable and random switching conditions received the same number of switch and nonswitch trials. For each trial, highly transparent textual cues indicated the nature of the task, and the appropriate response mapping was present in the upper corners of the screen. These cues were used to reduce working memory demands and were present for all three block types: single task, predictable switching, and random switching. The cues appeared simultaneously with each stimulus, and there was no delay between a response and the subsequent trial. Bivalent stimuli (stimuli relevant to either task) were present, even in single-task blocks. All tasks were programmed in E-Prime 1.1 (W. Schneider, Eschman, \& Zuccolotto, 2002). 
In the consonant or vowel/odd or even (CVOE) transfer task pair, participants saw a letter-number pair in the center of the screen and determined whether the letter was a consonant or a vowel or whether the number was odd or even. Participants first completed two singletask blocks: one of consonant-vowel trials and another of odd-even trials. They were then given two task-switching blocks: one of predictable switching and one of random switching. The order of these blocks was counterbalanced across participants. The cues, "consonant" or "odd" and "vowel" or "even" were present in the left- and right-hand corners of the screen. These cues were present for all blocks.

Training consisted of repeated practice on three different pairs of tasks. In light of work in the skill acquisition literature indicating that variability in training promotes greater transfer than does training using only one task (see Schmidt \& Bjork, 1992, for a review), three different task-switching training pairs were used.

The task-switching training tasks were the forward or backward/ greater or less than 50 task (FB50), the upper-or lowercase/divisible or not divisible by 5 task (ULD5), and the red or green/X or $O$ task (RGXO). The FB50 task required alternating between judging whether the letter was facing forward or backward and judging whether a number was greater or less than 50 . The cues for "Forward" or "Greater than 50" were in the upper left-hand corner, and the cues for "Backward" or "Less than 50" were in the upper righthand corner. In the ULD5 task, participants switched between judging whether a letter was upper- or lowercase and judging whether the number was divisible by 5 . The corresponding cues were "Upper" or "/5" on the left hand and "Lower" or Not $/ 5$ " on the right. In the RGXO task, participants were shown a red or green $\mathrm{X}$ or $\mathrm{O}$ and alternated between judging the color and judging the identity of the letter. The cues were "Red "or "X" on the left hand and "Green" or "O" on the right hand. Stimuli were in 24-point Courier New font.

Procedure. The experiment consisted of two 1-h sessions, with the second session occurring $24-48 \mathrm{~h}$ after the first. All participants were tested on random and predictable versions of the CVOE task at the beginning of the first session (pretest) and again at the end of the second (posttest). Both the pretest and posttest consisted of four 48-trial blocks: one predictable task-switching block, one random task-switching block, and two single-task blocks, throughout which participants performed only consonant-vowel judgments or oddeven judgments. Immediately following pretest and immediately preceding posttest, all participants performed a 48-trial single-task block of each of the six tasks used during training (forward or backward, greater or less than 50, upper- or lowercase, divisible or not divisible by 5 , red or green, and $\mathrm{X}$ or $\mathrm{O}$ ). This allowed the calculation of mixing costs on the training tasks for the switch-training groups for Sessions 1 and 2. Participants were always told the identity of the current block (single task, random, or predictable).

Training was broken up across sessions. The first 4 blocks of training were administered on Session 1 and the last 4 on Session 2 . The predictable and random switch-training groups received 8 blocks of practice ( 4 per day) on each of the three task-switching training tasks, for a combined total of 1,152 trials across the three task-pairs. The control group practiced each of the individual tasks alone in 12 single-task blocks of 96 trials across sessions, so that the number of trials of each individual task was the same between the switch-training and the control groups The only difference was the context: task switching versus single task. Each block was preceded by a 10-trial practice block, for which accuracy feedback was given. These trials were excluded from analysis.

\section{Results}

The findings will be presented in two sections. In the first, we will describe the training data. We examined the training data to ascertain that both random and predictable switch-training groups showed reliable mixing and switch costs during training and that these costs were reduced with practice. The second section will be concerned with the question of transfer of training and with whether the training groups showed a greater pre- to posttest cost reduction, as compared with the control group and with each other. To test for mixing and switch costs in both the training and transfer analyses, we specified two contrasts: a mixing-cost contrast that tested the mean RT of nonswitch trials against the mean RT of single-task trials and a switch-cost contrast that tested the mean RT of switch trials against the mean RT of nonswitch trials. For each analysis, we first will provide an overview of any main effects and then will proceed to the contrasts of interest.

Only RTs from correct trials were used. For each participant, we also excluded any RT faster or slower than $3 S D$ s from the condition mean (single task, nonswitch, or switch); this eliminated $0.02 \%$ of correct responses. For all analyses in all experiments reported, an $\alpha$ of .05 was set.

Training results. Both the accuracy and RT (see Table 1) data were submitted to a mixed factorial ANOVA, with task (FB50, ULD5, and RGXO), trial type (single task, nonswitch, and switch), and testing time (first block vs. last block) as within-subjects factors and group (predictable vs. random switch) as a between-subjects factor, with two planned comparisons specified: a testing time $\times$ switch cost contrast and testing time $\times$ mixing cost contrast.

For the accuracy data, the overall analysis showed significant main effects of task [FB50, $M=.90$; ULD5, $M=.98 ;$ RGXO, $M=.99 ; F(2,120)=1,316.9, \eta_{\mathrm{p}}^{2}=$

Table 1

Experiment 1: Mean Reaction Times (in Milliseconds) and Mixing and Switch Costs (Difference in Milliseconds), With Standard Deviations (SDs), for the First and Last Blocks of the Three Training Tasks

\begin{tabular}{|c|c|c|c|c|c|c|c|c|c|c|c|c|c|c|c|c|c|c|c|c|c|}
\hline \multirow[b]{3}{*}{ Task } & \multirow[b]{3}{*}{ Block } & \multicolumn{10}{|c|}{ Predictable Training Group } & \multicolumn{10}{|c|}{ Random Training Group } \\
\hline & & \multicolumn{2}{|c|}{$\begin{array}{c}\text { Single- } \\
\text { Task } \\
\text { Trials }\end{array}$} & \multicolumn{2}{|c|}{$\begin{array}{c}\text { Nonswitch } \\
\text { Trials }\end{array}$} & \multicolumn{2}{|c|}{$\begin{array}{l}\text { Switch } \\
\text { Trials }\end{array}$} & \multicolumn{2}{|c|}{$\begin{array}{c}\text { Mixing } \\
\text { Cost }\end{array}$} & \multicolumn{2}{|c|}{$\begin{array}{l}\text { Switch } \\
\text { Cost }\end{array}$} & \multicolumn{2}{|c|}{$\begin{array}{c}\text { Single- } \\
\text { Task } \\
\text { Trials }\end{array}$} & \multicolumn{2}{|c|}{$\begin{array}{c}\text { Nonswitch } \\
\text { Trials }\end{array}$} & \multicolumn{2}{|c|}{$\begin{array}{l}\text { Switch } \\
\text { Trials }\end{array}$} & \multicolumn{2}{|c|}{$\begin{array}{c}\text { Mixing } \\
\text { Cost }\end{array}$} & \multicolumn{2}{|c|}{$\begin{array}{l}\text { Switch } \\
\text { Cost }\end{array}$} \\
\hline & & $M$ & $S D$ & $M$ & $S D$ & $M$ & $S D$ & $M$ & $S D$ & $M$ & $S D$ & $M$ & $S D$ & $M$ & $S D$ & $M$ & $S D$ & $M$ & $S D$ & $M$ & $S D$ \\
\hline \multirow[t]{2}{*}{ FB50 } & First & 751 & 109 & 1,020 & 323 & 1,395 & 309 & 269 & 240 & 375 & 177 & 794 & 182 & 1,271 & 271 & 1,691 & 306 & 477 & 179 & 420 & 190 \\
\hline & Last & 685 & 102 & 740 & 169 & 1,011 & 245 & 55 & 128 & 271 & 152 & 707 & 124 & 1,026 & 215 & 1,412 & 313 & 319 & 151 & 386 & 187 \\
\hline \multirow[t]{2}{*}{ ULD5 } & First & 647 & 90 & 926 & 282 & 1,333 & 294 & 279 & 205 & 407 & 180 & 677 & 113 & 1,218 & 229 & 1,619 & 208 & 541 & 192 & 401 & 205 \\
\hline & Last & 589 & 64 & 714 & 130 & 973 & 199 & 125 & 93 & 259 & 120 & 603 & 91 & 986 & 178 & 1,276 & 207 & 383 & 140 & 290 & 139 \\
\hline \multirow[t]{2}{*}{ RGXO } & First & 588 & 95 & 889 & 183 & 1,027 & 180 & 301 & 146 & 138 & 145 & 616 & 102 & 913 & 161 & 1,022 & 180 & 297 & 118 & 109 & 109 \\
\hline & Last & 552 & 76 & 697 & 119 & 763 & 134 & 145 & 96 & 66 & 157 & 595 & 113 & 702 & 166 & 735 & 157 & 107 & 101 & 33 & 44 \\
\hline
\end{tabular}

Note-FB50, forward or backward/greater or less than 50; ULD5, upper or lower/divisible or not divisible by 5; RGXO, red or green/X or O. 
.96] and trial type [single task, $M=.99$; nonswitch, $M=$ .98 ; switch, $\left.M=.91 ; F(2,120)=756.2, \eta_{\mathrm{p}}^{2}=.93\right]$. Neither contrast was statistically significant [testing time $\times$ switch cost, $F(1,60)=2.0, p=.16, \eta_{\mathrm{p}}^{2}=.03$; testing time $\times$ mixing cost, $F<1$ ], suggesting that any changes in mixing or switch cost with practice were not due to any major changes in accuracy with practice.

The analysis of the RT data showed all main effects to be significant. There was an effect of testing time, with an overall reduction in RT from the first to last block $\left[F(1,60)=279.4, \eta_{\mathrm{p}}^{2}=.82\right]$. There was also an effect of task, with larger RTs for the FB50 and ULD5 tasks and smaller RTs for the RGXO task $\left[F(2,59)=199.4, \eta_{\mathrm{p}}^{2}=\right.$ .87]. There was a main effect of trial type, with larger RTs for switch trials, smaller RTs for nonswitch trials, and the smallest RTs for the single-task condition $[F(2,59)=$ $\left.453.2, \eta_{\mathrm{p}}^{2}=.94\right]$. Finally, there was a main effect of group, with an overall greater RT for the random training group $\left[F(1,60)=16.2, \eta_{\mathrm{p}}^{2}=.98\right]$.

Both mixing and switch costs were reduced considerably with practice, since both the testing time $\times$ mixing cost $\left[F(1,108)=126.6, \eta_{\mathrm{p}}^{2}=.54\right]$ and the testing time $\times$ switch cost $\left[F(1,108)=78.9, \eta_{\mathrm{p}}^{2}=.42\right]$ interactions were significant. We ran a follow-up analysis, adding the factor group to the testing time $\times$ mixing and testing time $\times$ switch comparisons to determine whether there were any differences in the amount of improvement seen in random switch versus predictable switching. The results indicate a trend toward a group difference in switch costs $[F(1,108)=$ $\left.3.7, p=.058, \eta_{\mathrm{p}}^{2}=.03\right]$, with a larger reduction with practice for the random training group than for the predictable training group, but there were no group differences in the amount of mixing cost reduction $(F<1)$.

Transfer data. Both accuracies and RTs were analyzed using a mixed factorial ANOVA with training group (predictable switch-training, random switch-training, control) as a between-subjects factor and the type of task-switching block (predictable, random), trial type (switch, nonswitch, single task) and testing time (pretest, posttest) as withinsubjects factors. We specified four comparisons to test for evidence of transfer: a group $\times$ testing time $\times$ switch cost contrast and a group $\times$ testing time $\times$ mixing cost contrast for both the predictable and the random transfer blocks.

The overall accuracy analysis showed main effects of transfer type $\left[F(1,90)=5.36, \eta_{\mathrm{p}}^{2}=.06\right]$, with greater accuracy for predictable switching (predictable, $M=.99$; random, $M=.98$ ) and trial type (single task, $M=.98$; nonswitch, $M=.99$; switch, $M=.98)[F(2,180)=6.9$, $\left.\eta_{\mathrm{p}}^{2}=.07\right]$. None of the switch or mixing cost comparisons were significant [predictable mixing cost $\times$ group $\times$ testing time, $F(2,90)=1.7, p=.19, \eta_{\mathrm{p}}^{2}=.04$; all other $F \mathrm{~s}<1$ ], suggesting that any pre- to posttest reductions in mixing or switch cost were not achieved at the expense of accuracy.

For the RT data, the overall analysis revealed main effects of testing time, with all RTs reduced by the second day $\left[F(1,90)=388.4, \eta_{\mathrm{p}}^{2}=.81\right]$; of trial type, with switch RTs longer than nonswitch RTs, which were larger than the single-task RTs $\left[F(2,180)=914.1, \eta_{\mathrm{p}}^{2}=.91\right]$; and of the type of switching block, with longer RTs for random switching than for predictable switching $[F(1,90)=106.0$, $\left.\eta_{\mathrm{p}}^{2}=.54\right]$. Figure 1 shows the condition means.
A

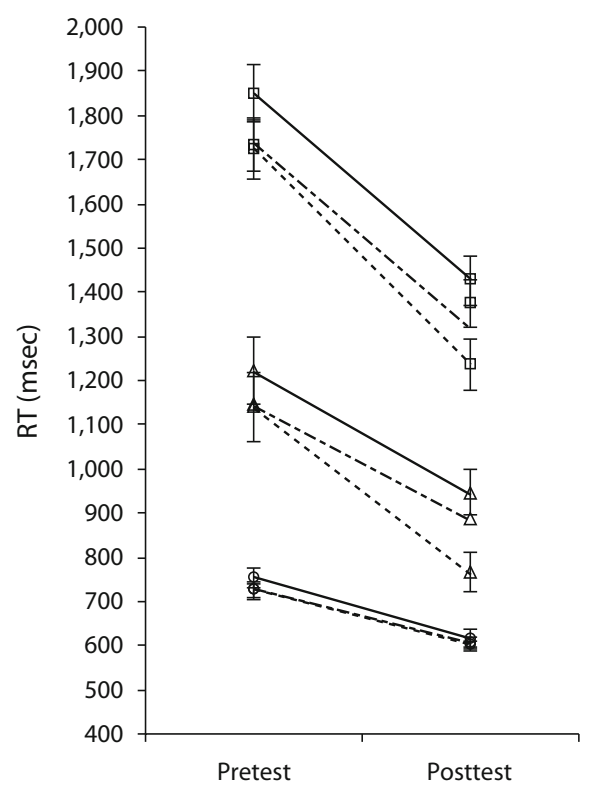

B

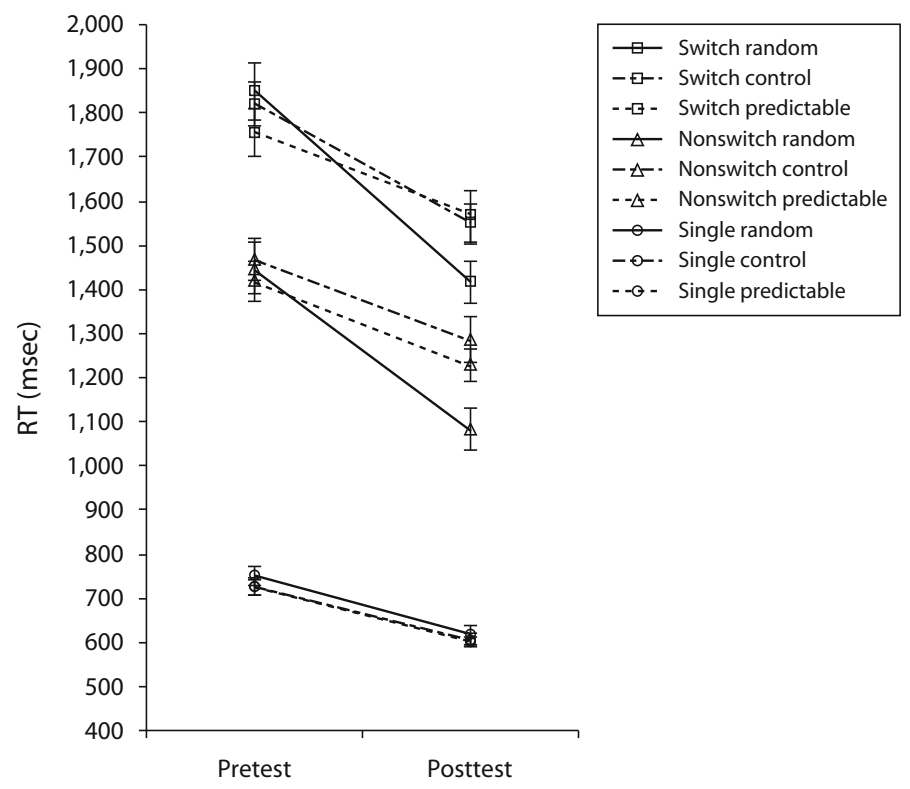

Figure 1. (A) Reaction time (RT) means for the predictable transfer task at pretest and posttest broken down by trial type (switch, nonswitch, and single task) and group (random switch-training, control, and predictable switch-training) in Experiment 1. (B) Same RT means for the random transfer task. Error bars reflect standard errors. 
A

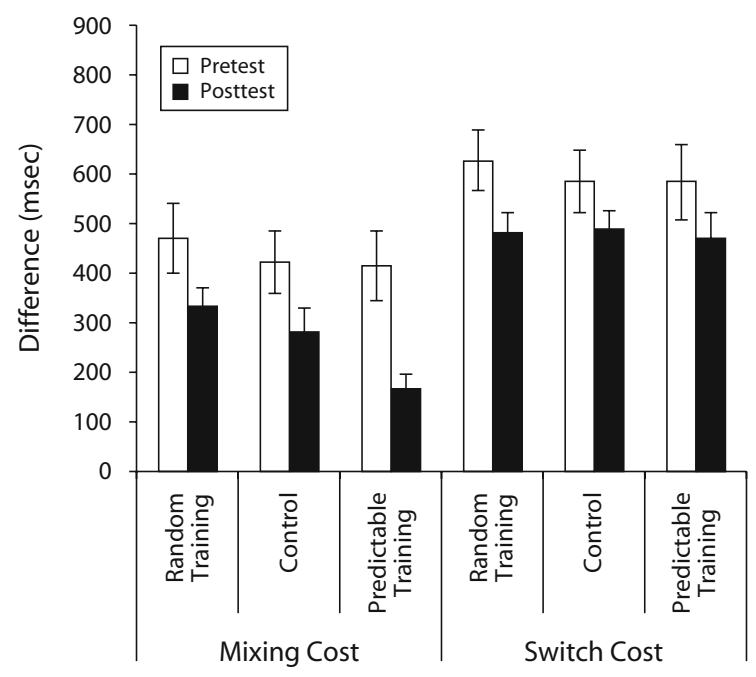

B

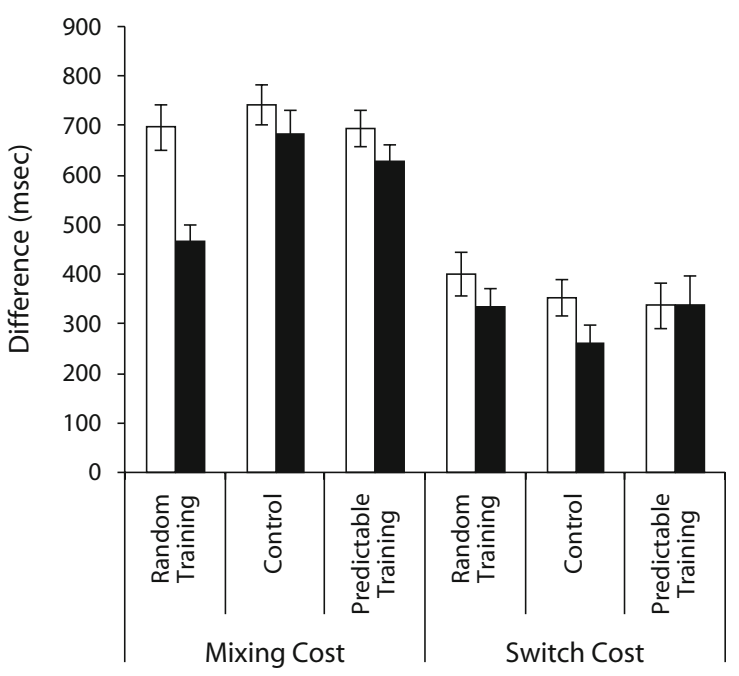

Figure 2. (A) Mixing and switch costs for predictable transfer in Experiment 1. (B) Mixing and switch costs for random transfer in Experiment 1. Error bars reflect standard errors.

Of the four comparisons designed to test for transfer of training, only the group $\times$ testing time $\times$ mixing cost comparison in the random transfer block was significant $\left[F(2,90)=6.9, \eta_{\mathrm{p}}^{2}=.13\right]$. Although an inspection of the mixing costs for the predictable transfer condition, shown in Figure 2A, suggests a greater pre- to posttest reduction for the predictable training group, this trend was not statistically significant $\left[F(2,90)=1.2, p=.30, \eta_{\mathrm{p}}^{2}=.02\right]$. Neither switch cost comparison was significant $\left(F_{\mathrm{S}}<1\right)$.

To determine the exact nature of improvement in the random transfer block as measured by mixing cost, we tested each training group separately against the control group and against each other. The random switch training group showed significantly greater pre- to posttest reductions in mixing cost for the random transfer block than did both the control group $\left[F(1,60)=11.5, \eta_{\mathrm{p}}^{2}=.16\right]$ and the predictable switch training group $[F(1,60)=9.7$, $\left.\eta_{\mathrm{p}}^{2}=.14\right]$, whereas the predictable training group and the control group did not differ from each other $(F<1)$.

\section{Discussion}

This experiment was designed to examine whether the practice-based improvements frequently observed in task-switching performance can generalize to a different switching context. Although both predictable and random switch-training groups demonstrated clear practice-based reductions in both mixing and switch costs for the three different task pairs on which they trained, strong evidence of transfer was observed only from practice on random switching to the random switching block of the transfer task as measured by mixing cost. On the other hand, switch cost showed no clear pattern of transfer in either the random or the predictable transfer blocks. These results present a mixed picture of the extent to which transfer of training is possible in the task-switching paradigm. As compared with a control group that did not practice switching between tasks, the random switch-training group showed greater reductions in both switch and nonswitch RTs on a randomly switching transfer task. However, this superior performance did not appear to transfer to a predictable block of the same transfer task. Although there was a trend toward a similar pattern for the predictable training group, with a greater pre- to posttest reduction of mixing cost in the predictable block of the transfer task, this reduction did not reach statistical significance.

The lack of transfer between the two types of switching suggests that the benefits observed were not likely due to simple increases in arousal after practicing switching. It would also appear to argue against general improvements in the resolution of stimulus ambiguity or in the inhibition of an inappropriate response, because these presumably would be common to both types of switching. Earlier, we noted that differences in cost have been reported between random and predictable switching. This difference has been due largely to the nonswitch trials. Rogers and Monsell (1995) initially argued that task-set reconfiguration is complete with the first nonswitch trial and that no further adjustments are necessary. In their data for predictable switching, subsequent nonswitch trials showed no further reductions in RT. However, later studies using random switching reported a gradual decline in RT across nonswitch trials (Meiran, Chorev, \& Sapir, 2000; Monsell et al., 2003; Salthouse, Fristoe, McGuthry, \& Hambrick, 1998). Milán et al. (2005) interpreted this difference in the pattern of performance following a switch as evidence that different mechanisms are necessary in reconfiguring the task-set for both predictable and random switching. Alternatively, Monsell et al. put forth that the same mechanism is used to reconfigure taskset in both predictable and random switches. However, if the identity of future trials is uncertain, as it is in random switching, the task-set bias may be attenuated if participants do not fully commit to the current task set. 
Either interpretation may help explain the apparent lack of transferable improvement between random and predictable switching. It is worth noting that in our data, the observed transferable improvement affected the switch and nonswitch trials roughly equally, so that the difference between the training groups was reflected in mixing cost and not in switch cost, whereas hypotheses concerning task-set reconfiguration are concerned with the difference between the two trial types.

\section{EXPERIMENT 2}

In this experiment, we attempted to replicate the transfer of training seen in Experiment 1. The only difference was the addition of a 200-msec interval between the cues that indicated the target stimulus and the task to be performed. This change served two purposes. First, a replication of our earlier result using a different cue-to-stimulus interval (CSI) would help establish that our earlier finding was not peculiar to rapid switching with no opportunity for preparation. Second, the addition of a preparatory interval between the cue and stimulus may ameliorate possible differences in task-set bias between predictable and random switches (i.e., if participants can rely on getting advance notice of the next trial type, they may show a greater commitment to the current task set). This may allow for transfer from training on one type of switching to another.

\section{Method}

Participants. Seventy-five University of Michigan undergraduates participated for a $\$ 20$ payment and were assigned randomly to the three groups: random switch-training $(n=25)$, predictable switch-training $(n=25)$, and control $(n=25)$.

Procedure. The design, tasks, and procedure differed from those reported in Experiment 1 only with the addition of a 200-msec CSI used for all switching blocks, both random and predictable.

\section{Results}

The data were analyzed exactly as in Experiment 1.

Training data. Data from 2 participants were lost due to computer error and were excluded from the analyses of training data.

The overall analysis of training accuracy showed main effects of task [FB50, $M=.91$; ULD5, $M=.98$; RGXO, $M=.98 ; F(2,92)=179.2, \eta_{\mathrm{p}}^{2}=.79$ ], trial type [single task,
$M=.98 ;$ nonswitch, $M=.97 ;$ switch, $M=.92 ; F(2,92)=$ $262.2, \eta_{\mathrm{p}}^{2}=.85$ ], and group [random, $M=.96$; predictable, $\left.M=.95 ; F(1,46)=4.24, \eta_{\mathrm{p}}^{2}=.08\right]$. Neither contrast was statistically significant [testing time $\times$ switch cost, $F(1,46)=2.6, p=.11, \eta_{\mathrm{p}}^{2}=.05$; testing time $\times$ mixing cost, $F<1$ ], suggesting no significant change in accuracy from the first block of training to the last.

For the RT data (see Table 2), the results were similar to those in Experiment 1; there were main effects of testing time $\left[F(1,46)=310.3, \eta_{\mathrm{p}}^{2}=.87\right]$, task $[F(2,45)=220.7$, $\left.\eta_{\mathrm{p}}^{2}=.83\right]$, and trial type $\left[F(2,45)=324.9, \eta_{\mathrm{p}}^{2}=.88\right]$. Specifically, RTs decreased significantly from the first block of training to the last; the slowest RTs were for the FB50 task, and the fastest were for the RGXO task; the longest RTs were for switch trials, and the shortest were for singletask trials. However, unlike in Experiment 1, there was no overall effect of group $\left[F(1,46)=1.1, p=.30, \eta_{\mathrm{p}}^{2}=.02\right]$.

Transfer data. The overall accuracy analysis showed main effects of transfer type $\left[F(1,72)=12.3, \eta_{\mathrm{p}}^{2}=.15\right]$, with better accuracy for predictable switching $(M=.98$; random, $M=.97$ ) and for trial type (single task, $M=.98$; nonswitch, $M=.98$; switch, $M=.97)[F(1,72)=42.5$, $\left.\eta_{\mathrm{p}}^{2}=.37\right]$. None of the contrasts were significant [predictable: testing time $\times$ group $\times$ switch, $F(2,72)=1.5, p=$ $.23, \eta_{\mathrm{p}}^{2}=.04$; all other $F_{\mathrm{s}}<1$ ].

In the overall analysis of the RT data (shown in Figure 3$)$, there were main effects of testing time $[F(1,72)=$ $\left.205.8, \eta_{\mathrm{p}}^{2}=.74\right]$, trial type $\left[F(1,72)=1,206.3, \eta_{\mathrm{p}}^{2}=.94\right]$, and transfer type $\left[F(1,72)=54.0 \eta_{\mathrm{p}}^{2}=.43\right]$, similar to those in Experiment 1.

The contrast results mirrored those seen in Experiment 1, with only the group $\times$ testing time $\times$ mixing cost comparison for the random switching transfer block reaching significance $\left[F(2,72)=6.9, \eta_{\mathrm{p}}^{2}=.16\right]$ (see Figure 4). Testing each training group separately against the control group and against each other showed that the random training group had significantly greater pre- to posttest reductions in mixing cost for the random transfer block than did both the control group $\left[F(1,48)=16.9, \eta_{\mathrm{p}}^{2}=.26\right]$ and the predictable switch-training group $\left[F(1,48)=4.9, \eta_{\mathrm{p}}^{2}=.09\right]$, whereas the predictable training group and the control group did not differ from each other $\left[F(1,48)=1.6, p=.21, \eta_{\mathrm{p}}^{2}=.03\right]$.

The predictable mixing cost comparison was not significant $\left[F(2,72)=1.6, p=.20, \eta_{\mathrm{p}}^{2}=.04\right]$. As in Experiment 1 ,

Table 2

Experiment 2: Mean Reaction Times (in Milliseconds) and Mixing and Switch Costs (Difference in Milliseconds), With Standard Deviations (SDs), for the First and Last Blocks of the Three Training Tasks

\begin{tabular}{|c|c|c|c|c|c|c|c|c|c|c|c|c|c|c|c|c|c|c|c|c|c|}
\hline \multirow[b]{3}{*}{ Task } & \multirow[b]{3}{*}{ Block } & \multicolumn{10}{|c|}{ Predictable Training Group } & \multicolumn{10}{|c|}{ Random Training Group } \\
\hline & & \multicolumn{2}{|c|}{$\begin{array}{c}\text { Single- } \\
\text { Task } \\
\text { Trials }\end{array}$} & \multicolumn{2}{|c|}{$\begin{array}{c}\text { Nonswitch } \\
\text { Trials }\end{array}$} & \multicolumn{2}{|c|}{$\begin{array}{l}\text { Switch } \\
\text { Trials }\end{array}$} & \multicolumn{2}{|c|}{$\begin{array}{c}\text { Mixing } \\
\text { Cost }\end{array}$} & \multicolumn{2}{|c|}{$\begin{array}{c}\text { Switch } \\
\text { Cost }\end{array}$} & \multicolumn{2}{|c|}{$\begin{array}{c}\text { Single- } \\
\text { Task } \\
\text { Trials }\end{array}$} & \multicolumn{2}{|c|}{$\begin{array}{c}\text { Nonswitch } \\
\text { Trials }\end{array}$} & \multicolumn{2}{|c|}{$\begin{array}{l}\text { Switch } \\
\text { Trials }\end{array}$} & \multicolumn{2}{|c|}{$\begin{array}{c}\text { Mixing } \\
\text { Cost }\end{array}$} & \multicolumn{2}{|c|}{$\begin{array}{l}\text { Switch } \\
\text { Cost }\end{array}$} \\
\hline & & $M$ & $S D$ & $M$ & $S D$ & $M$ & $S D$ & $M$ & $S D$ & $M$ & $S D$ & $M$ & $S D$ & $M$ & $S D$ & $M$ & $S D$ & $M$ & $\overline{S D}$ & $M$ & $S D$ \\
\hline \multirow[t]{2}{*}{ FB50 } & First & 739 & 94 & 975 & 239 & 1,403 & 289 & 236 & 210 & 428 & 222 & 697 & 154 & 891 & 169 & 1,256 & 187 & 194 & 173 & 365 & 167 \\
\hline & Last & 642 & 82 & 672 & 170 & 929 & 251 & 30 & 141 & 257 & 157 & 658 & 121 & 702 & 106 & 966 & 182 & 44 & 118 & 264 & 157 \\
\hline \multirow[t]{2}{*}{ ULD5 } & First & 645 & 68 & 846 & 236 & 1,256 & 237 & 201 & 209 & 410 & 182 & 654 & 179 & 806 & 189 & 1,160 & 248 & 152 & 205 & 354 & 167 \\
\hline & Last & 574 & 71 & 654 & 176 & 817 & 208 & 80 & 170 & 163 & 81 & 557 & 71 & 656 & 124 & 832 & 144 & 99 & 105 & 176 & 87 \\
\hline \multirow[t]{2}{*}{ RGXO } & First & 540 & 63 & 675 & 134 & 810 & 125 & 135 & 122 & 135 & 94 & 535 & 172 & 657 & 133 & 717 & 165 & 122 & 193 & 60 & 72 \\
\hline & Last & 511 & 65 & 522 & 66 & 575 & 79 & 11 & 43 & 53 & 46 & 482 & 71 & 486 & 87 & 510 & 104 & 4 & 70 & 24 & 53 \\
\hline
\end{tabular}

Note-FB50, forward or backward/greater or less than 50; ULD5, upper or lower/divisible or not divisible by 5; RGXO, red or green/X or O. 
A

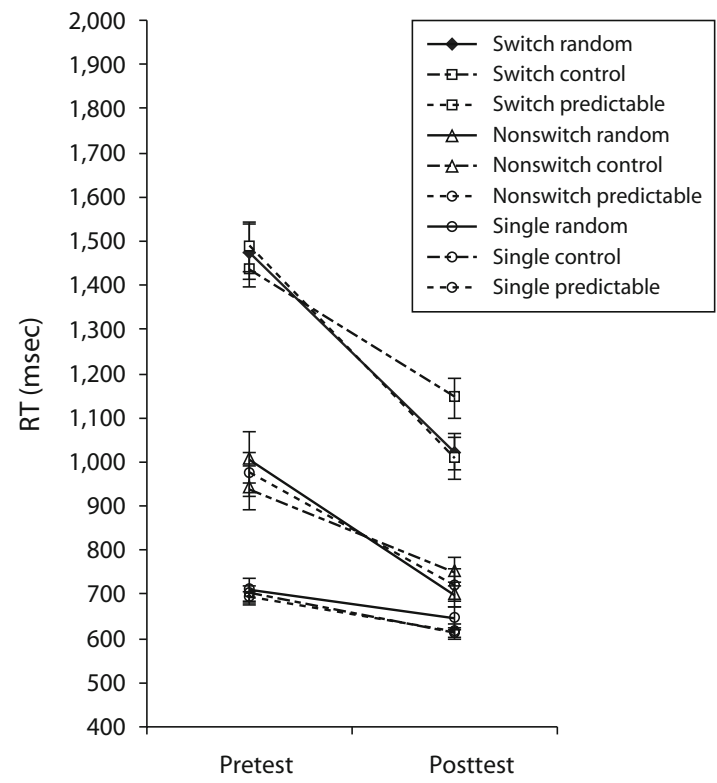

B

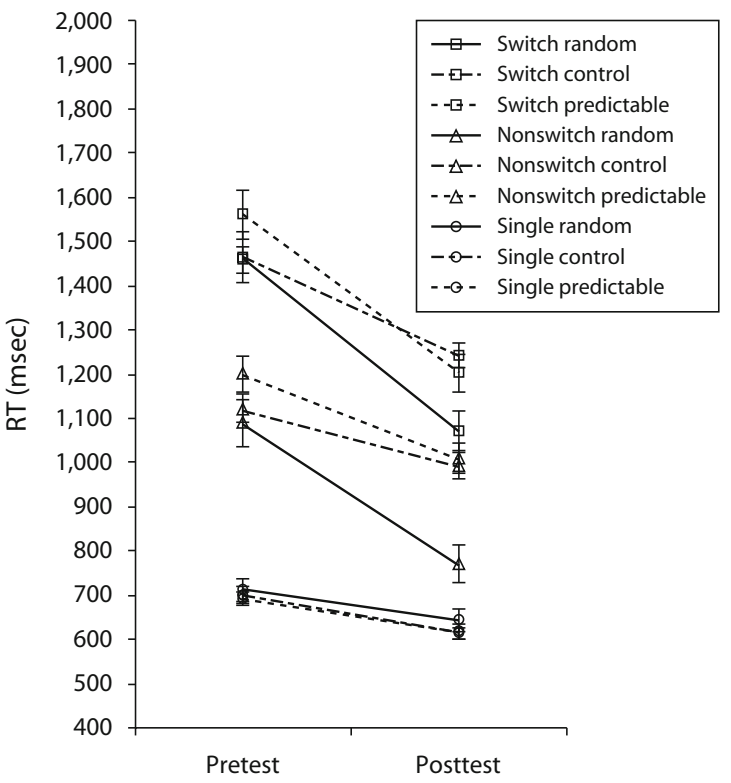

Figure 3. (A) Reaction time (RT) means for the predictable transfer task at pretest and posttest broken down by trial type (switch, nonswitch, and single task) and group (random switch-training, control, and predictable switch-training) in Experiment 2. (B) Same RT means for the random transfer task. Error bars reflect standard errors.

a visual inspection of the data hinted of a difference between at least one training group and the control group at posttest. However, this time it was the random training group with a trend toward a greater reduction in mixing cost, as compared with the control group $\left[F(1,48)=3.18, p=.08, \eta_{\mathrm{p}}^{2}=.06\right]$, whereas the predictable group did not differ from the control group $(F<1)$. Neither of the switch comparisons was significant [predictable testing time $\times$ group $\times$ switch cost, $F(2,72)=1.4, p=.25, \eta_{\mathrm{p}}^{2}=.04$; random testing time $\times$ group $\times$ switch cost, $\left.F(2,72)=1.5, p=.24, \eta_{\mathrm{p}}^{2}=.04\right]$.

\section{Discussion}

In this experiment, we attempted to replicate the findings of Experiment 1, but with the addition of a 200-msec
A

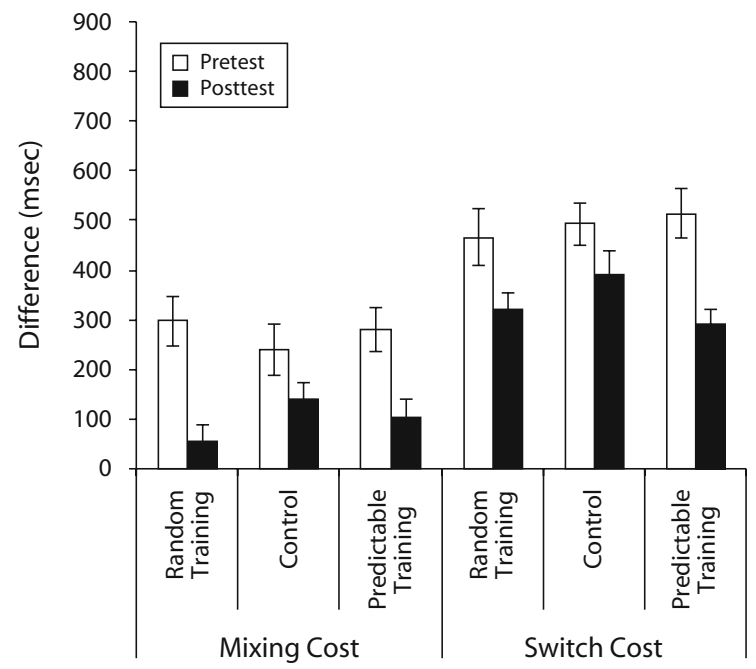

B

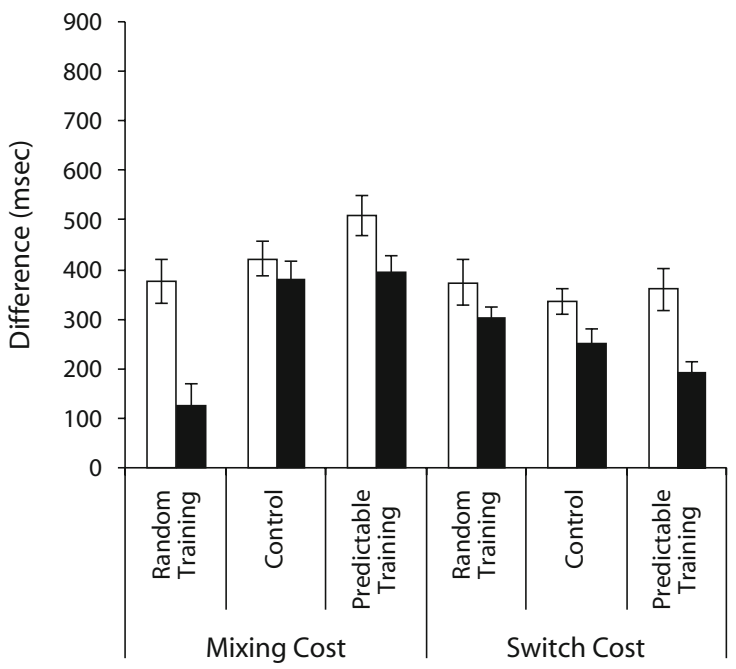

Figure 4. (A) Mixing and switch costs for predictable transfer in Experiment 2. (B) Mixing and switch costs for random transfer in Experiment 2. Error bars reflect standard errors. 
preparatory interval between the cue and the target stimulus. The pattern of results was very similar. The only statistically reliable evidence of transferable improvement was that for the random training group for the random transfer mixing cost comparison. However, as in Experiment 1, a visual examination of the predictable transfer data suggested a greater pre- to posttest reduction for at least one training group. In the first experiment, the predictable training group appeared to have a slight advantage, but in Experiment 2, the random switch-training group appeared to show greater improvement than did the control group. These differences did not reach statistical significance in either experiment, nor did any pre- to posttest differences in switch cost. To test whether these differences could become significant with a larger $N$, we combined the data across Experiments 1 and 2, ran the same contrasts, and found the same results, with a robust pretest-to-posttest mixing cost improvement for the random training group on the random transfer task $\left[F(2,165)=13.6, \eta_{\mathrm{p}}^{2}=.14\right]$, a nonsignificant difference in the predictable mixing contrast $\left[F(2,165)=1.4, p=.24, \eta_{\mathrm{p}}^{2}=.02\right]$, and no reliable differences in switch costs $\left(F_{\mathrm{S}}<1\right)$.

The results from these experiments raise two main questions: What is it that is improving with the random transfer, and why are there significant, but not predictable, effects for random switching? As we noted earlier, random and predictable switching involve many of the same processes. What differs is knowledge of the identity of the next trial type and the necessity of the cues. In predictable switching, if participants are keeping track of the sequence, they know with certainty whether the next trial will switch. However, in random switching, the identity of the next trial is uncertain until the cue appears. This level of uncertainty in random switching has been hypothesized as leading participants to commit less fully to the current task set (Monsell et al., 2003). Also, Dreisbach et al. (2002) have hypothesized that the level of cognitive control exerted can be adjusted on the basis of the probability of a switch's occurring. Their work using cues that predict the next trial with varying degrees of certainty has shown that expectancies affect performance on both switch and nonswitch trials (Dreisbach \& Haider, 2006; Dreisbach et al., 2002). Therefore, what participants may be learning over training and then transferring to new task pairs is an optimal adjustment of task-set bias on different trial types. This may explain the greater degree of transfer for random switching. In predictable switching, the set of expectancies can be learned easily, whereas in random switching, participants likely need additional practice. There is some evidence for this in the training data. Although there was no interaction between testing time and training group in a comparison of the first and last training blocks; when we tested the first block versus the fifth (i.e., the first block of training on the second day of the study), there was a significant interaction between testing time and group, with the predictable switching group showing a larger decrease in mixing cost $\left[F(2,216)=17.9, \eta_{\mathrm{p}}^{2}=.14\right]$. However, this difference in improvement was gone after three additional blocks of practice. Therefore, that the control group may have had some appreciable improvement from their pretest exposure to predictable switching may account for the weakness of the posttest differences between groups on the predictable transfer task.

A second reason that predictable transfer was so weak may be that participants use different strategies in switching predictably. In our variant of the task - each trial is cued and occurs in a predictable sequence-participants may either use their knowledge of the sequence or rely on the cues. Therefore, it is possible that the results seen in the predictable transfer data are due to a mixture of different strategies across participants. We included cues in our predictable switching so that working memory demands would not differ between predictable and random task sequences. Cues also helped get participants back on sequence if they made an error. Without cues, a participant can easily lose track of which trial they are performing and then stay offsequence for the rest of a block, even though, after the mistake, participants may think that they are performing the correct task. This can make error analysis difficult. In trying to avoid such problems, we may have inadvertently created another. Future research using predictable switching should either include measures such as monitoring eye movements to determine whether participants are relying on the cues or use cueless predictable switching.

In random switching, participants must rely on the cues to identify the current task. Therefore, a second possible source of improvement with practice is the use of the cues. During the training component, participants may have improved in retrieving a particular task set in response to a specific cue. Naturally, this would not account for any improvement in switching between a new pair of tasks. However, it may be that participants are learning a strategy specific to the type of cues, textual task labels placed in the corners of the screen, used during both training and transfer. Given that the cues in Experiments 1 and 2 appear in corners of the screen, participants may have learned to detect changes in the cues without having to saccade to the corners. This would have improved RT on both switch and nonswitch trials. Therefore, in our last experiment, we tested whether we could replicate the pattern of transfer seen from random training to a random posttest measure, using different types of cues at training and at pre- and posttest.

\section{EXPERIMENT 3}

In Experiment 3, we tested whether the transferable improvement in random switching with practice may be seen across different cuing paradigms. In random switching, participants depend entirely on external, explicit cues, which may be of varying degrees of transparency. For example, in Experiments 1 and 2, the textual cues "Consonant or Vowel" or "Odd or Even" were highly transparent. However, many experiments use more arbitrary cues, such as the color of a box surrounding the stimulus or the location of the stimulus on a screen. In Experiments 1 and 2, the same type of textual and highly transparent cues was used during both the training and the transfer portions of 
the experiment. This raised the possibility that any transfer observed could have been due to the participants learning cue-specific strategies.

However, if the transfer is seen from one type of cue to another, then any improvements in switching performance at posttest are unlikely to be due to a cue-specific strategy. Therefore, we used two cue types at pre- and posttest: the highly transparent textual cue used in our earlier experiments and a second, more arbitrary cue based on the spatial location of the stimulus. Participants in the switch-training group received practice on the same three training tasks as those used in our earlier experiments, but using both the spatial cue used at pretest and a second type of arbitrary cue, the color of a box surrounding the target stimulus, rather than a textual cue. A control group practiced the same tasks in a nonswitching context. If transferable improvement is the result of particular demands or strategies associated with a specific type of cue, we should expect transfer for only the spatial cue used during training, pretests, and posttests. However, if transfer results from changes in processes that are independent of the cues practiced during training, we should expect to see transferable improvement for both the textual and the spatial cues.

\section{Method}

Participants. Forty-eight University of Michigan and Washington University students participated for a payment of \$20 or course credit. Participants were assigned randomly to the switch-training $(n=24)$ or control $(n=24)$ group.

Design. We employed a pretest-posttest design similar to that in Experiments 1 and 2, with three major changes. We had only two groups, a random switch-training group and a control group that trained on a single task. Without the need to match the number of switch and nonswitch trials to a predictable condition, tasks were switched completely at random. We also added a within-subjects variable, the type of cue. During switch-training, a line cue and a box cue (described below) indicated which task was to be performed, and at transfer, one switching block used the line cue and one used the textual cues used in Experiments 1 and 2.

Tasks and Stimuli. The training and transfer tasks were the same as those in Experiments 1 and 2. In all switching blocks, tasks switched unpredictably, with a $200-\mathrm{msec}$ CSI.

The CVOE task was again used to measure transfer. However, two types of cues were used: the explicit textual cue used earlier (the words "Consonant" and "Vowel" presented in the upper corners of the screen for letter judgments and the words "Odd" and "Even" for number judgments) and a newly introduced spatial line cue (the letter-number pair appeared above a black line in the center of the screen for letter judgments and below the line for number judgments).

The same three task-switching training tasks were practiced by the random switch-training group, which used two types of cues: the line cue and a box cue, in which the target stimulus appeared in a box located in the center of the screen. If the box was blue, participants performed one task; if it was yellow, they performed the other. A card showing all the task mappings was placed next to the computer in case a participant forgot which task to perform if the stimulus was above or below the line or in a blue or yellow box on any particular task. All stimuli were presented in 24-point Courier New font. The textual cue was never used during training.

Procedure. The experiment consisted of two 1-h sessions, with the second session occurring $24-48 \mathrm{~h}$ after the first. Both groups of participants were measured on the CVOE task at the beginning of the first session (pretest) and again at the end of the second (posttest). At both pretest and posttest, participants first completed two single-task blocks, a 48-trial block of solely consonant-vowel judgments and a 48-trial block of odd-even judgments. Both the textual and the line cues were present for the single-task block. Participants then completed two 64-trial CVOE switching blocks, with one block using the line and the other using the textual cue. The order of these blocks was counterbalanced across participants. The remainder of Session 1 and the beginning of Session 2 consisted of the training component of the study. Both the switch-training and the control groups first completed a 48-trial, single-task block of each of the six component tasks that made up the three switching tasks, with the line cue present on the first 24 trials and the box cue present on the second 24 trials. The switch-training group then practiced eight 48 -trial blocks of each of the three switching tasks, with half of the blocks using the line cue and half using the box cue, for a combined total of 1,152 mixed-task trials across both days of training. As in Experiments 1 and 2, the control group practiced each individual task in 12 single-task blocks of 96 trials. The same cues and spatial location of the stimulus were used for the singletask blocks as for the switching blocks, so that the switch-training and the control groups received the same visual display on any given trial. Each block was preceded by a 10-trial practice block, for which participants were given accuracy feedback. These trials were excluded from the analyses.

\section{Results}

Training results. Data from 1 participant were lost due to computer error. Both the accuracy and RT data were submitted to a within-subjects ANOVA, with testing time (first block vs. last block), task (FB50, ULD5, and RGXO), trial type (single task, nonswitch, and switch), and cue type (line and box) as factors. Practice effects were examined by specifying two contrasts for the two cue types, testing time $\times$ mixing cost and testing time $\times$ switch cost.

In the overall accuracy analysis, there were main effects of task [FB50, $M=.95$; ULD5, $M=.96$; RGXO, $M=$ $.95 ; F(2,44)=3.6, \eta_{\mathrm{p}}^{2}=.14$ ], of cue type [line, $M=.96$; box, $\left.M=.95 ; F(1,22)=4.3, \eta_{\mathrm{p}}^{2}=.16\right]$, and of trial type [single task, $M=.97$; nonswitch, $M=.96$; switch, $M=$ $\left..95 ; F(2,44)=10.1, \eta_{\mathrm{p}}^{2}=.32\right]$, with greater accuracy for the single-task trials. However, none of the practice-based contrasts were significant [box cue: testing time $\times$ switch, $F(1,22)=1.9, p=.18, \eta_{\mathrm{p}}^{2}=.08 ;$ all other $\left.F \mathrm{~s}<1\right]$.

For the RT data (see Table 3), there were main effects of testing time, with a reduction in overall RT from the first blocks to the last $\left[F(1,22)=114.8, \eta_{\mathrm{p}}^{2}=.84\right]$; of trial type $\left[F(2,21)=180.8, \eta_{\mathrm{p}}^{2}=.95\right]$; of $\operatorname{task}[F(2,21)=27.6$, $\left.\eta_{\mathrm{p}}^{2}=.72\right]$, with the longest RTs for the FB50 task; and of cue type $\left[F(1,22)=195.7, \eta_{\mathrm{p}}^{2}=.90\right]$, with longer RTs for blocks using the box cue. Both switch cost contrasts were significant, indicating robust practice effects for switch cost for both line $\left[F(1,22)=38.74, \eta_{\mathrm{p}}^{2}=.64\right]$ and box $\left[F(1,22)=43.57, \eta_{\mathrm{p}}^{2}=.66\right]$ cue types. Mixing cost was reduced significantly in the line cue condition $[F(1,22)=$ $\left.7.51, \eta_{\mathrm{p}}^{2}=.25\right]$. It was also reduced from the first to the last block of training for the box cue condition, although this did not reach the level of statistical significance set for this study $\left[F(1,22)=3.9, p=.06, \eta_{\mathrm{p}}^{2}=.15\right]$.

Transfer results. The accuracy data were submitted to a repeated measures ANOVA with training group (random training vs. control) as a between-subjects factor and 
Table 3

Experiment 3: Mean Reaction Times (in Milliseconds) and Mixing and Switch Costs (Difference in Milliseconds), With Standard Deviations (SDs), for the First and Last Blocks of the Three Training Tasks

\begin{tabular}{|c|c|c|c|c|c|c|c|c|c|c|c|c|c|c|c|c|c|c|c|c|c|}
\hline \multirow[b]{3}{*}{ Task } & \multirow[b]{3}{*}{ Block } & \multicolumn{10}{|c|}{ Line Cue } & \multicolumn{10}{|c|}{ Box Cue } \\
\hline & & \multicolumn{2}{|c|}{$\begin{array}{c}\text { Single- } \\
\text { Task } \\
\text { Trials }\end{array}$} & \multicolumn{2}{|c|}{$\begin{array}{c}\text { Nonswitch } \\
\text { Trials } \\
\end{array}$} & \multicolumn{2}{|c|}{$\begin{array}{l}\text { Switch } \\
\text { Trials }\end{array}$} & \multicolumn{2}{|c|}{$\begin{array}{c}\text { Mixing } \\
\text { Cost }\end{array}$} & \multicolumn{2}{|c|}{$\begin{array}{c}\text { Switch } \\
\text { Cost }\end{array}$} & \multicolumn{2}{|c|}{$\begin{array}{c}\text { Single- } \\
\text { Task } \\
\text { Trials }\end{array}$} & \multicolumn{2}{|c|}{$\begin{array}{c}\text { Nonswitch } \\
\text { Trials } \\
\end{array}$} & \multicolumn{2}{|c|}{$\begin{array}{l}\text { Switch } \\
\text { Trials }\end{array}$} & \multicolumn{2}{|c|}{$\begin{array}{c}\text { Mixing } \\
\text { Cost }\end{array}$} & \multicolumn{2}{|c|}{$\begin{array}{c}\text { Switch } \\
\text { Cost }\end{array}$} \\
\hline & & $M$ & $S D$ & $M$ & $S D$ & $M$ & $S D$ & $M$ & $S D$ & $M$ & $S D$ & $M$ & $S D$ & $M$ & $S D$ & $M$ & $S D$ & $M$ & $S D$ & $M$ & $S D$ \\
\hline \multirow[t]{2}{*}{ FB50 } & First & 683 & 83 & 673 & 91 & 992 & 239 & -10 & 75 & 319 & 192 & 677 & 73 & 807 & 171 & 1,194 & 187 & 130 & 166 & 387 & 160 \\
\hline & Last & 626 & 100 & 578 & 94 & 722 & 153 & -48 & 109 & 144 & 202 & 621 & 99 & 678 & 121 & 1,001 & 169 & 57 & 136 & 323 & 113 \\
\hline \multirow[t]{2}{*}{ ULD5 } & First & 577 & 48 & 596 & 88 & 795 & 156 & 19 & 166 & 199 & 114 & 569 & 47 & 726 & 175 & 1,145 & 296 & 157 & 154 & 419 & 267 \\
\hline & Last & 524 & 53 & 501 & 55 & 622 & 103 & -23 & 66 & 121 & 77 & 502 & 48 & 727 & 104 & 874 & 119 & 225 & 75 & 121 & 80 \\
\hline \multirow[t]{2}{*}{ RGXO } & First & 450 & 38 & 600 & 127 & 901 & 125 & 150 & 124 & 301 & 92 & 431 & 41 & 742 & 179 & 1,148 & 194 & 311 & 200 & 406 & 182 \\
\hline & Last & 410 & 35 & 545 & 108 & 727 & 104 & 135 & 103 & 183 & 71 & 399 & 37 & 608 & 124 & 920 & 160 & 275 & 90 & 318 & 105 \\
\hline
\end{tabular}

Note_FB50, forward or backward/greater or less than 50; ULD5, upper or lower/divisible or not divisible by 5; RGXO, red or green/X or O.

type of cue (line vs. textual), trial type (switch, nonswitch, or single task), and testing time (pretest vs. posttest) as within-subjects factors. Two contrasts were specified for both the line cue transfer block and the textual cue transfer: a group $\times$ testing time $\times$ mixing cost and a group $\times$ testing time $\times$ switch cost comparison.

Accuracy was very high overall. The overall analysis showed only a main effect of trial type [single task, $M=$ .97 ; nonswitch, $M=.97$; switch, $M=.95 ; F(1,46)=$ $\left.18.7, \eta_{\mathrm{p}}^{2}=.30\right]$. None of the mixing or switch contrasts were significant [textual: group $\times$ testing time $\times$ mixing cost, $F(1,46)=1.2, p=.28, \eta_{\mathrm{p}}^{2}=.03$; all other $\left.F \mathrm{~s}<1\right]$.

The same analysis was applied to the RT data (see Figure 5). All main effects were significant. Overall, RT declined from pretest to posttest $\left[F(1,46)=421.9, \eta_{\mathrm{p}}^{2}=.90\right]$.
RTs were affected by the type of cue used, with faster RTs for the line cue $\left[F(1,46)=210.1, \eta_{\mathrm{p}}^{2}=.82\right]$, as well as by the trial type, with longer RTs on switch trials $[F(2,92)=$ $\left.474.1, \eta_{\mathrm{p}}^{2}=.91\right]$. Finally, pre- to posttest RT reduction was larger for the training group than for the control group $\left[F(1,46)=9.7, \eta_{\mathrm{p}}^{2}=.17\right]$. However, no interactions involving testing time, group, and cue type were significant $\left(F_{\mathrm{S}}<1\right)$, indicating that any pre- to posttest differences between the training and control groups were not due to the type of cue used.

Both the line and textual cue mixing cost comparisons were significant [line, $F(1,46)=12.16, \eta_{\mathrm{p}}^{2}=.21$; textual, $\left.F(1,46)=4.4, \eta_{\mathrm{p}}^{2}=.09\right]$, with a greater pre- to posttest reduction in mixing cost for the switch-training group than for the control group, as shown in Figure 6. Neither switch
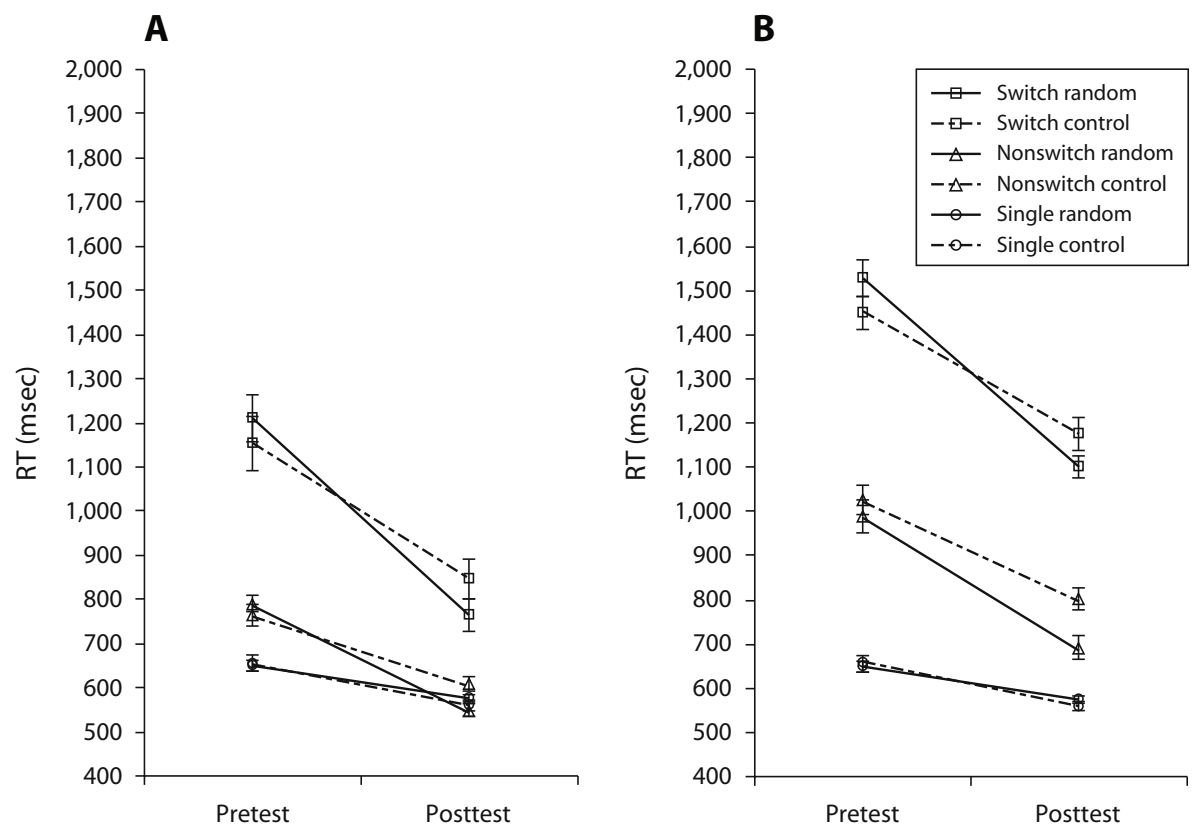

Figure 5. (A) Individual mean reaction times (RTs) broken down by trial type and group for the line version of the transfer task in Experiment 3. (B) Same data for the textual transfer task in Experiment 3. Error bars reflect standard errors. 

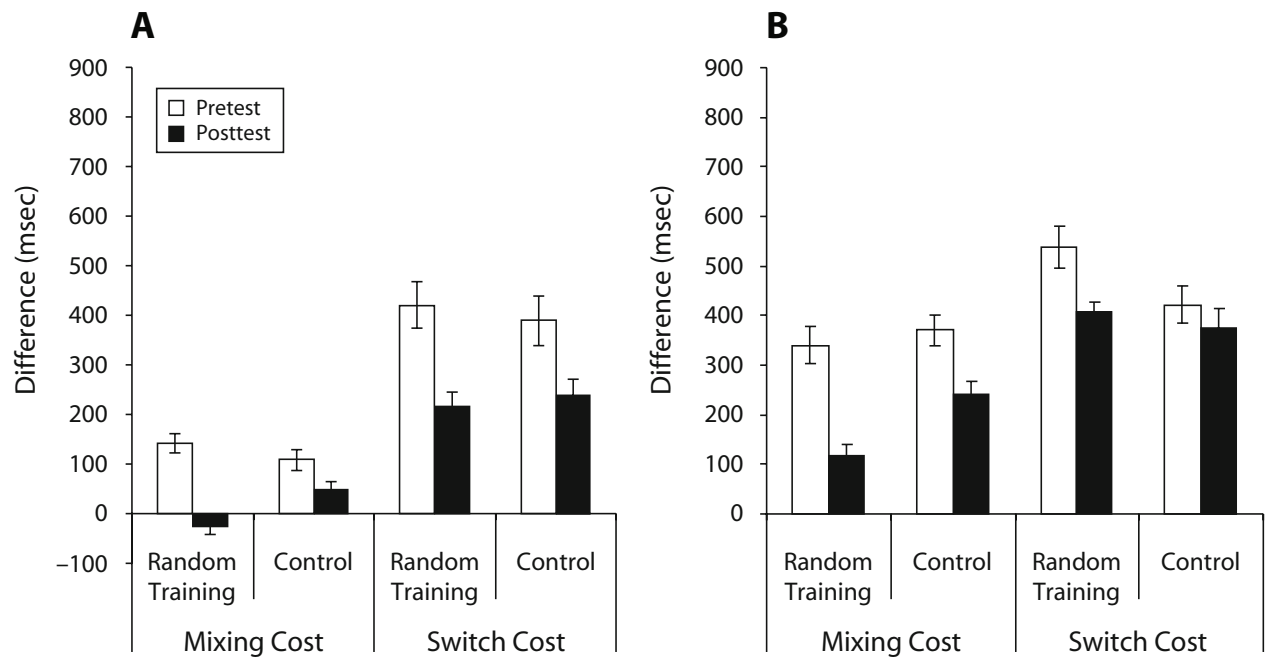

Figure 6. (A) Mixing and switch costs for the line transfer in Experiment 3. (B) Mixing and switch costs in the textual transfer block in Experiment 3. Error bars reflect standard errors.

cost contrast was significant [line, $F(1,46)=1.2, p=.29$, $\eta_{\mathrm{p}}^{2}=.03$; textual, $\left.F(1,46)=2.5, p=.12, \eta_{\mathrm{p}}^{2}=.05\right]$.

\section{Discussion}

The results of this experiment demonstrate that the transferable improvement seen after training on random task switching can occur between different types of cues. For both the line cue practiced during training and the unpracticed textual cue, the training group showed larger reductions in the mixing cost comparison than did the control group. The pre- to posttest reductions on the textual cue transfer task for the training group in this experiment $(223 \mathrm{msec})$ were similar in magnitude to those seen in Experiment $2(250 \mathrm{msec})$. This indicates that the transfer observed in all three experiments was not the result of cue-specific strategies.

The design of Experiment 3 also made it unlikely that the training group learned to anticipate better when switch and nonswitch trials would occur. This was a possibility in Experiments 1 and, 2 where random switching was constrained so the number of switch and nonswitch trials in a block would match that in the predictable switching condition. With practice, participants may have learned to gauge the likelihood of a switch or nonswitch implicitly, on the basis of previous trials. However, in Experiment 3, trials were allowed to switch completely at random. As a result, sequences in which two tasks alternated rapidly in succession or where three or more nonswitch trials occurred in a row were not unusual and had no effect on the trial composition of the rest of the block.

A third possibility was that training on random switching improved the participants' ability to resolve task-set competition. Task-set competition, theoretically, should be highest on trials following a switch, because both task sets will have been active on the previous two trials. Therefore, we decided to run a secondary analysis in which we considered not only whether the current trial was a switch or a nonswitch, but also the identity of the trial immediately before it. To do so, we collapsed across cue types and rebinned the trials into four new types: a switch following a switch ( $\mathrm{SwSw}$ ), a switch following a nonswitch (NsSw), a nonswitch following a switch ( $\mathrm{SwNs}$ ), and a nonswitch following a nonswitch (NsNs). We submitted these RTs to a repeated measures ANOVA with training group as a between-subjects factor and testing time, current trial type, and preceding trial type as within-subjects factors. There was a significant interaction between testing time, group, and preceding trial type, with greater pre- to posttest improvements for the training group on trials preceded by a switch $[F(1,46)=6.8$, $\left.\eta_{\mathrm{p}}^{2}=.13\right]$. The four-way interaction with current trial type did not reach significance, although a trend was present $\left[F(1,46)=3.5, p=.07, \eta_{\mathrm{p}}^{2}=.07\right]$. However, this trend was difficult to interpret, given the pretest differences between groups for the $\mathrm{SwSw}$ trials.

In light of the three-way interaction between testing time, group, and preceding trial type, we collapsed over current trial type and tested the pre- to posttest improvement seen for the training group for trials following a switch against the training group improvement for trials following a nonswitch $\left[F(1,23)=13.8, \eta_{\mathrm{p}}^{2}=.37\right]$, against the control group improvement for trials following a switch $\left[F(1,46)=23.2, \eta_{\mathrm{p}}^{2}=.34\right]$ and against results for trials following a nonswitch $\left[F(1,46)=31.9, \eta_{\mathrm{p}}^{2}=.41\right]$. There was no pre- to posttest difference between trials following a switch and those following a nonswitch for the control group $(F<1)$.

As can be seen in Figure 7, the transfer effect was stronger for trials immediately following a switch and weaker for trials following a nonswitch. Therefore, it appears that the training group was faster at recovering from an unexpected switch and that this faster recovery improved performance on the following trial, regardless of whether it was a switch or a nonswitch. 


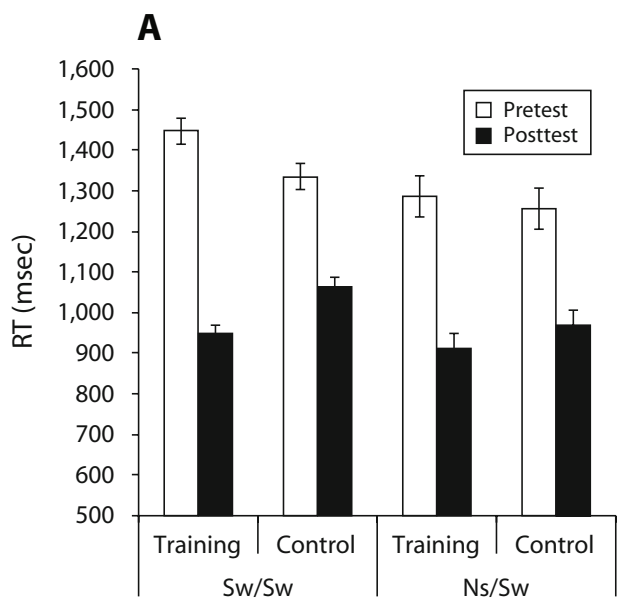

Previous Trial/Current Trial

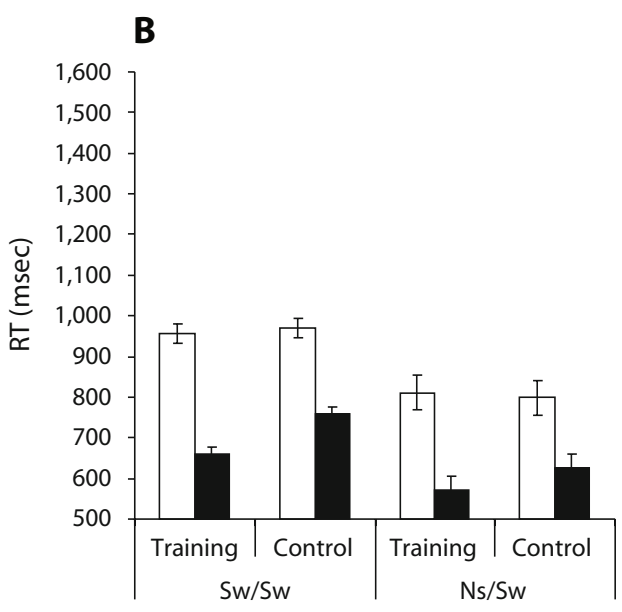

Previous Trial/Current Trial

Figure 7. (A) Mean reaction times (RTs) for switch (Sw) trials as a function of testing time, group, and identity of the previous trial in Experiment 3. (B) Same information for the nonswitch (Ns) trials. Error bars reflect standard errors.

\section{GENERAL DISCUSSION}

Evidence of transferable improvement in task-switching performance is of considerable interest for our understanding of task switching and of the possibility of transferable improvement in executive functions. The most consistent evidence of transfer across three experiments was seen for random switching as measured by the mixing cost comparison. In contrast, there was little evidence of transfer as measured by switch cost. The reason for this became apparent in Experiment 3, in which we learned that transfer was strongest for trials immediately following a switch; this was true regardless of whether the trial was another switch trial or a nonswitch.

Thus, the parameter that improves with training is best characterized as recovery from an unexpected switchunexpected because we found no evidence of transfer from practice on predictable to random. As was discussed above, one well-known difference between predictable and random switching lies in the first nonswitch trial (Monsell et al., 2003). In predictable switching, the first nonswitch trial does not differ from ensuing nonswitch trials, whereas in random switching, participants need several nonswitch trials to recover fully from a switch. This has been attributed to differences in task set bias in random switching, with participants unwilling to commit fully to the new task set. However, the data from our final experiment argue against any deliberate biasing of task set by participants, because both switch and nonswitch RTs are larger after a switch trial, and both show improvement at transfer. Therefore, the difference between random and predictable switching may be that an expected switch is less disruptive than an unexpected one. This is similar to the results of recent studies of task interruptions in which participants who were warned of an interruption recovered more quickly than participants who were not (Trafton, Altmann, Brock, \& Mintz, 2003). Especially intriguing from our perspective was that, with practice, participants who received no warning improved their ability to recover from a task interruption with practice.

A number of different processes have been hypothesized as being involved in switching tasks. On the basis of these initial data, we propose that the most likely source of transferable improvement lies in the training participants' ability to resolve task-set conflicts (Kray \& Lindenberger, 2000; Mayr, 2003). Task-set competition would be especially large after a switch, because both task sets would have been active in the two previous trials. The successful resolution of such competition may be accomplished through increased attentional control (Hübner, Futterer, \& Steinhauser, 2001), additional set-selection or decision processes (Rubin \& Meiran, 2005; Rubinstein, Meyer, \& Evans, 2001; Steinhauser \& Hübner, 2005), or inhibitory processing at the level of the task set, the response set, or the stimulus (Mayr, 2001).

Of these three, inhibition appears to be the least likely prospect, because there is evidence that task-set inhibition is automatic and is not penetrable by preparation (Dreisbach et al., 2002; Mayr \& Keele, 2000). Stimulusand response-based inhibition also appears unlikely. As we noted, the lack of transfer between predictable and random switching would argue against stimulus- and response-based processes. Instead, improvements in attentional control represent a more likely prospect. A sequence effect similar to that seen in Experiment 3 has been observed in an attention-switching task in which participants had to maintain two internal counters (Gehring, Bryck, Jonides, Albin, \& Badre, 2003). Such a task is an excellent candidate for a future test of transfer. If training on task switching leads to improved conflict resolution between two internal representations, then transfer from task switching to an attention-switching task, such as the one described above, could be possible. However, transfer would not occur if the transfer seen in task switching is 
the result of improvements in decision processes specific to task sets.

Task-switching performance as measured by switch cost showed little evidence for transferable improvement in the task-switching paradigms used in these experiments. A lack of transfer is consistent with some theoretical interpretations of switch cost-for example, those that attribute switch costs to task- or stimulus-level priming (e.g., Wylie \& Allport, 2000). The pattern of results seen here naturally does not rule out the possibility of transferable improvements in switch costs in future studies using different variations of the task-switching paradigm. However, for researchers interested in training or remediation of executive function, these results illustrate that within a given executive task, there may be multiple measures of a putative executive process and that one may be more sensitive or appropriate for the measure of transferable improvement than another. Many experiments investigating task switching have reported only switch cost as their dependent measure. In terms of our study, this would have resulted in no evidence of transferable improvement in task switching.

\section{CONCLUSION}

The study of transferable improvement in task switching not only adds to our understanding of the different processes involved in task switching, but also adds to a small but growing literature of studies demonstrating transferable improvement in executive processes (Bherer et al., 2005; Dowsett \& Livesey, 2000; Klingberg et al., 2002; Kramer et al., 1995). Given the rising interest in the extent to which executive processes, such as task switching, can benefit from various interventions from such cognitive training or rehabilitation programs in impaired populations (Butler \& Copeland, 2002; Kramer, Hahn, \& McAuley, 2000; Minear \& Shah, 2006; Rueda, Rothbart, McCandliss, Saccomanno, \& Posner, 2005), it is important to establish the extent to which, and the conditions under which, training on these processes can yield measurable improvements.

\section{AUTHOR NOTE}

We thank Beth Campbell, Melissa Janik, and Rachel Orlowski for their assistance with data collection; Erin Regen for other assistance; and Dave Balota, Sandy Hale, and Joel Myerson for their comments. Address correspondence to M. Minear, Washington University, St. Louis, MO (e-mail: mereditheminear@gmail.com).

\section{REFERENCES}

Bherer, L., Kramer, A. F., Peterson, M. S., Colcombe, S., ErickSON, K., \& BECIC, E. (2005). Training effect on dual-task performance: Are there age-related differences in plasticity of attentional control? Psychology \& Aging, 20, 695-709.

Braver, T. S., Reynolds, J. R., \& Donaldson, D. I. (2003). Neural mechanisms of transient and sustained cognitive control during task switching. Neuron, 39, 713-726.

Butler, R. W., \& Copeland, D. R. (2002). Attentional processes and their remediation in children treated for cancer: A literature review and the development of a therapeutic approach. Journal of the International Neuropsychological Society, 8, 115-124.
Cepeda, N. J., Cepeda, M. L., \& Kramer, A. F. (2000). Task switching and attention deficit hyperactivity disorder. Journal of Abnormal Child Psychology, 28, 213-226.

Cepeda, N. J., Kramer, A. F., \& Gonzalez de Sather, J. C. M. (2001). Changes in executive control across the life span: Examination of task-switching performance. Developmental Psychology, 37, 715-730.

Dowsett, S. M., \& Livesey, D. J. (2000). The development of inhibitory control in preschool children: Effects of "executive skills" training. Developmental Psychobiology, 36, 161-174.

Dreisbach, G., \& Haider, H. (2006). Preparatory adjustment of cognitive control in the task switching paradigm. Psychonomic Bulletin \& Review, 13, 334-338.

Dreisbach, G., Haider, H., \& Kluwe, R. H. (2002). Preparatory processes in the task-switching paradigm: Evidence from the use of probability cues. Journal of Experimental Psychology: Learning, Memory, \& Cognition, 28, 468-483.

Gehring, W. J., Bryck, R. L., Jonides, J., Albin, R. L., \& Badre, D. (2003). The mind's eye, looking inward? In search of executive control in internal attention shifting. Psychophysiology, 40, 572-585.

Hübner, R., Futterer, T., \& Steinhauser, M. (2001). On attentional control as a source of residual shift costs: Evidence from twocomponent task shifts. Journal of Experimental Psychology: Learning, Memory, \& Cognition, 27, 640-653.

Jersild, A. T., (1927). Mental set and shift. Archives of Psychology, 14, 89.

Keele, S. W., \& Rafal, B. (2000). Deficits of attentional set in frontal patients. In S. Monsell \& J. Driver (Eds.), Attention and performance XVIII: Control of cognitive processes (pp. 627-652). Cambridge, MA: MIT Press.

Klingberg, T., Forssberg, H., \& Westerberg, H. (2002). Training of working memory in children with ADHD. Journal of Clinical \& Experimental Neuropsychology, 24, 781-791.

Kramer, A. F., Hahn, S., \& Gopher, D. (1999). Task coordination and aging: Explorations of executive control processes in the task switching paradigm. Acta Psychologica, 101, 339-378.

Kramer, A. F., Hahn, S., \& MCAuley, E. (2000). Influence of aerobic fitness on the neurocognitive function of older adults. Physical Activity \& Aging, 4, 379-385.

Kramer, A. F., Larish, J. F., \& Strayer, D. L. (1995). Training for attentional control in dual task settings: A comparison of young and older adults. Journal of Experimental Psychology: Applied, 1, 50-76.

KrAY, J., \& EPPINGER, B. (2006). Effects of associate learning on age differences in task-set switching. Acta Psychologica, 123, 187-203.

Kray, J., Li, K. Z. H., \& LindenBERGER, U. (2002). Age-related changes in task-switching components: The role of task uncertainty. Brain \& Cognition, 49, 363-381.

Kray, J., \& Lindenberger, U. (2000). Adult age differences in taskswitching. Psychology \& Aging, 15, 126-147.

MAYR, U. (2001). Age differences in the selection of mental sets: The role of inhibition, stimulus ambiguity, and response-set overlap. Psychology \& Aging, 16, 96-109.

MAYR, U. (2003). Towards principles of executive control: How mental sets are selected. In R. H. Kluwe, G. Lüer, \& F. Rösler (Eds.), Principles of learning and memory (pp. 223-240). Berlin: Birkhäuser.

Mayr, U., \& KeEle, S. W. (2000). Changing internal constraints on action: The role of backward inhibition. Journal of Experimental Psychology: General, 129, 4-26.

MAYr, U., \& KLIEGL, R. (2003). Differential effects of cue changes and task changes on task-set selection costs. Journal of Experimental Psychology: Learning, Memory, \& Cognition, 29, 362-372.

MeIRAN, N. (1996). Reconfiguration of processing mode prior to task performance. Journal of Experimental Psychology: Learning, Memory, \& Cognition, 22, 1423-1442.

Meiran, N., Chorev, Z., \& Sapir, A. (2000). Component processes in task switching. Cognitive Psychology, 41, 211-253.

Meiran, N., Friedman, G., \& Yehene, E. (2004). Parkinson's disease is associated with goal setting deficits during task switching. Brain \& Cognition, 54, 260-262.

Milán, E. G., Sanabria, D., Tornay, F., \& González, A. (2005). Exploring task-set reconfiguration with random task sequences. Acta Psychologica, 118, 319-331. 
Minear, M., \& SHaH, P. (2006). Sources of working memory deficits in children and possibilities for remediation. In S. J. Pickering (Ed.), Working memory and education. (pp. 273-307). London: Elsevier.

Miyake, A., Friedman, N. P., Emerson, M. J., Witzki, A. H., HowERTER, A., \& WAGER, T. D. (2000). The unity and diversity of executive functions and their contributions to complex "frontal lobe" tasks: A latent variable analysis. Cognitive Psychology, 41, 49-100.

Monsell, S., Sumner, P., \& Waters, H. (2003). Task-set reconfiguration with predictable and unpredictable task switches. Memory \& Cognition, 31, 327-342.

Rogers, R. D., \& Monsell, S. (1995). Costs of a predictable switch between simple cognitive tasks. Journal of Experimental Psychology: General, 124, 207-231.

Rubin, O., \& MEIRAN, N. (2005). On the origins of the task mixing cost in the cuing task-switching paradigm. Journal of Experimental Psychology: Learning, Memory, \& Cognition, 31, 1477-1491.

Rubinstein, J. S., Meyer, D. E., \& Evans, J. E. (2001). Executive control of cognitive processes in task switching. Journal of Experimental Psychology: Human Perception \& Performance, 27, 763-797.

Rueda, M. R., Rothbart, M. K., McCandliss, B. D., Saccomanno, L., \& Posner, M. I. (2005). Training, maturation, and genetic influences on the development of executive attention. Proceedings of the $\mathrm{Na}$ tional Academy of Sciences, 102, 14931-14936.

Salthouse, T. A., Fristoe, N., McGuthry, K. E., \& Hambrick, D. Z. (1998). Relation of task switching to speed, age, and fluid intelligence. Psychology \& Aging, 13, 445-461.

SchMidT, R. A., \& BJoRK, R. A. (1992). New conceptualizations of practice: Common principles in three paradigms suggest new concepts for training. Psychological Science, 3, 207-217.

SchneIder, D. W., \& Logan. G. D. (2005). Modeling task switching without switching tasks: A short-term priming account of explicitly cued performance. Journal of Experimental Psychology: General, 134, 343-367.

Schneider, W., Eschman, A., \& Zuccolotto, A. (2002). E-Prime user's guide. Pittsburgh: Psychology Software Tools.

SoHn, M.-H., \& CARLSON, R. A. (2000). Effects of repetition and foreknowledge in task-set reconfiguration. Journal of Experimental Psychology: Learning, Memory, \& Cognition, 26, 1445-1460.

Sohn, M.-H., Ursu, S., Anderson, J. R., Stenger, V. A., \& Carter, C. S. (2000). The role of prefrontal cortex and posterior parietal cortex in task switching. Proceedings of the National Academy of Sciences, 97, 13448-13453.

Steinhauser, M., \& HüBner, R. (2005). Mixing costs in task shifting reflect sequential processing stages in a multicomponenet task. Memory \& Cognition, 33, 1484-1494.

Tornay, F. J., \& Milán, E. G. (2001). A more complete task-set reconfiguration in random than in predictable task switch. Quarterly Journal of Experimental Psychology, 54A, 785-803.

Trafton, J. G., Altmann, E. M., Brock, D. P., \& Mintz, F. E. (2003). Preparing to resume an interrupted task: Effects of prospective goal encoding and retrospective rehearsal. International Journal of Human-Computer Studies, 58, 583-603.

Verhaeghen, P., Cerella, J., \& BasaK, C. (2004). A working memory workout: How to expand the focus of serial attention from one to four items in 10 hours or less. Journal of Experimental Psychology: Learning, Memory, \& Cognition, 30, 1322-1337.

Wylie, G., \& AllpoRT, A. (2000). Task switching and the measurement of "switch costs." Psychological Research, 63, 212-233.

(Manuscript received August 16, 2006; revision accepted for publication July 1, 2008.) 